\title{
A review of the benefits of early treatment initiation with single-pill combinations of telmisartan with amlodipine or hydrochlorothiazide
}

\author{
This article was published in the following Dove Press journal: \\ Vascular Health and Risk Management \\ 12 September 2013 \\ Number of times this article has been viewed
}

Julian Segura

Luis Miguel Ruilope

Department of Nephrology, Hospital

12 de Octubre, Madrid, Spain
Correspondence: Julian Segura Hypertension Unit, Department of Nephrology, Hospital 12 de Octubre, Avda Córdoba, Madrid 2804I, Spain

Tel +34913908198

Fax+349I 3908035

Email hta@juliansegura.com
Abstract: This review discusses the rationale for earlier use of single-pill combinations (SPCs) of antihypertensive drugs, with a focus on telmisartan/amlodipine (T/A) and telmisartan/ hydrochlorothiazide $(\mathrm{T} / \mathrm{H}) \mathrm{SPC}$. Compared with the respective monotherapies, the oncedaily T/A and T/H SPCs have been shown to result in significantly higher blood pressure (BP) reductions, BP goal rates, and response rates in patients at all stages of hypertension. As expected, BP reductions are highest with the highest dose (T80/A10 and T80/H25) SPCs. Subgroup analyses of the telmisartan trials have reported the efficacy of both SPCs to be consistent, regardless of the patients' age, race, and coexisting diabetes, obesity, or renal impairment. In patients with mild-to-moderate hypertension, the T/A combination provides superior 24-hour BP-lowering efficacy compared with either treatment administered as monotherapy. Similarly, the T/H SPC treatment provides superior 24-hour BP-lowering efficacy, especially in the last 6 hours relative to other renin-angiotensin system inhibitor-based SPCs. The T/A SPC is associated with a lower incidence of edema than amlodipine monotherapy, and the T/H SPC with a lower incidence of hypokalemia than hydrochlorothiazide monotherapy. Existing evidence supports the use of the T/A SPC for the treatment of hypertensive patients with prediabetes, diabetes, or metabolic syndrome, due to the metabolic neutrality of both component drugs, and the use of the T/H SPC for those patients with edema or in need of volume reduction.

Keywords: calcium-channel blocker, essential hypertension, diuretic, primary care physician, renin-angiotensin system inhibitor

\section{Introduction}

The treatment and control of hypertension remain less than optimal, despite the proven benefits of treatment in reducing cardiovascular morbidity and mortality. ${ }^{1,2}$ Therapeutic inertia, ie, the treating physician's failure to increase therapy when treatment goals are unmet, is one of the reasons for the high prevalence of uncontrolled hypertension. A retrospective cohort study of a large number of patients showed that reducing treatment inertia by $50 \%$ led to improvement in goal-rate attainment from $45 \%$ to $66 \%$ over a 1 -year period. ${ }^{3}$ Similarly, in a cross-sectional observational study in an outpatient setting, adherence to treatment guidelines and involvement of the physician were observed to result in a significantly higher percentage of patients achieving blood pressure (BP) goals. ${ }^{4}$

At least $75 \%$ of patients with hypertension require combination therapy to achieve BP targets. ${ }^{5}$ Treatment initiation with combination therapy has been shown to result in 
higher goal rates and reduction in the risk of cardiovascular (CV) events and death in a population-based, nested, casecontrol study and a retrospective analysis of electronic medical charts. ${ }^{6,7}$

Renin-angiotensin system (RAS) inhibitors are commonly used as a part of combination therapy, ${ }^{8,9}$ because of their proven $\mathrm{CV}$ benefits ${ }^{10,11}$ and the reduced risk of new-onset diabetes. ${ }^{12}$ RAS inhibitors offer benefits in patients with a greater risk of renal damage, such as those with diabetes and high-normal BP or overt hypertension, due to their superior protective effect against initiation and progression of nephropathy, ${ }^{8,11}$ and in patients with renal disease, to reduce and slow progression to end-stage renal disease and CV events. ${ }^{9}$

Angiotensin-receptor antagonists (ARBs) have better treatment adherence than angiotensin-converting enzyme inhibitors, ${ }^{13}$ better tolerability, and significantly lower rates of cough and angioedema. ${ }^{10,14}$ Among the ARBs, telmisartan has the most favorable pharmacokinetic profile, providing consistent BP reductions over 24 hours and beyond, ${ }^{15}$ and offers $\mathrm{CV}$ risk prevention in patients at high $\mathrm{CV}$ risk. ${ }^{10}$ Telmisartan is the only ARB approved for the reduction of $\mathrm{CV}$ morbidity in patients with manifest atherothrombotic $\mathrm{CV}$ disease (history of coronary heart disease, stroke, or peripheral artery disease) or diabetes mellitus, with documented target-organ damage. ${ }^{16,17}$

This review discusses the rationale for earlier use of telmisartan-based therapies, and in particular the evidence for choosing between calcium-channel blocker (CCB) and hydrochlorothiazide (HCTZ) combinations.

\section{RAS inhibitors, CCBs, and HCTZ: the cornerstones of combination antihypertensive therapy}

The American Society of Hypertension recommends an RAS inhibitor in addition to either a CCB or a diuretic, preferably as a single-pill combination (SPC) when convenience outweighs all other considerations. ${ }^{18}$ In the ACCOMPLISH (Avoiding Cardiovascular events through COMbination therapy in Patients LIving with Systolic Hypertension) trial involving 11,506 high-risk patients assigned to an RAS inhibitor plus a diuretic or CCB, RAS inhibitors plus a CCB reduced $\mathrm{CV}$ morbidity and mortality more than an RAS inhibitor plus a diuretic combination; ${ }^{19}$ the RAS inhibitor plus CCB combination also slowed the progression of nephropathy in a subgroup of patients with chronic kidney disease and minimal or no albuminuria. ${ }^{20}$ The combination is also beneficial in high-risk hypertensive patients, such as those with diabetes and/or existing CV disease. ${ }^{21}$ The beneficial effects of a RAS inhibitor plus a thiazide diuretic combination in lowering CV risk were shown in ADVANCE (Action in Diabetes and Vascular Disease: Preterax and Diamicron MR Controlled Evaluation), PROGRESS (Perindopril Protection Against Recurrent Stroke Study), and HYVET (Hypertension in the Very Elderly Trial) studies. ${ }^{22-25}$

\section{Achieving BP control with combination therapy: evidence from telmisartan clinical trials}

The once-daily telmisartan/amlodipine (T/A) combination has been shown to result in significantly higher BP reductions, $\mathrm{BP}$ goal rates, and response rates in patients at all stages of hypertension, compared with the respective monotherapies; the reductions were greatest with telmisartan $80 \mathrm{mg}$ plus amlodipine $10 \mathrm{mg}$ (T80/A10). ${ }^{26-28} \mathrm{In}$ a subgroup analysis of patients with moderate-to-severe hypertension, the T80/A10 combination provided significantly greater BP lowering than A10 monotherapy, with $85 \%$ of patients achieving their diastolic BP (DBP) goal. The incidence of peripheral edema was also lower in the combination group. ${ }^{29}$ In a large, combined analysis of 5,100 patients ( $24 \%$ with diabetes mellitus, $56 \%$ with obesity) from eight studies of 8 weeks' duration, T80/A10 combination therapy was associated with significantly higher BP goal-attainment rates and significantly greater reductions in BP compared with telmisartan or amlodipine monotherapy. The most significant differences were noted in patients whose treatment was initiated with combination therapy, and as early as 1 week after treatment initiation. ${ }^{30}$

Similarly, the once-daily telmisartan plus HCTZ $(\mathrm{T} / \mathrm{H})$ combination has been shown to result in significantly higher BP reductions and response rates in patients with mild-to-moderate hypertension, compared with the respective monotherapies after 7-8 weeks of treatment. ${ }^{27,31-34}$ Significantly higher reductions in BP and a higher proportion of patients reaching target $\mathrm{BP}$ were observed with the highest dose of telmisartan $80 \mathrm{mg}$ plus HCTZ $25 \mathrm{mg}$ (T80/ H25) than with telmisartan $80 \mathrm{mg}$ plus HCTZ $12.5 \mathrm{mg}$ (T80/H12.5) after 8 weeks of treatment. ${ }^{35}$ In patients with moderate-to-severe hypertension (stage 2 , defined as mean seated trough cuff systolic BP $[\mathrm{SBP}] \geq 160 \mathrm{mmHg}$ and $\mathrm{DBP} \geq 100 \mathrm{mmHg}),{ }^{36}$ initial antihypertensive treatment with T80/H25 resulted in significantly greater reductions in BP and in more patients achieving BP target and SBP response (defined as $<140 \mathrm{mmHg}$ or $\geq 15 \mathrm{mmHg}$ reduction from baseline) after 7 weeks compared with T80 monotherapy. 
The antihypertensive efficacy of T80/H25 was observed as early as 2 weeks after the start of treatment. ${ }^{37}$

The telmisartan SPCs are also effective in providing 24-hour BP-lowering efficacy. In patients with mild-tomoderate hypertension, the $\mathrm{T} / \mathrm{A}$ combination provided significantly higher 24-hour BP-lowering efficacy compared with the respective monotherapies after 8 weeks of treatment. ${ }^{38}$ In previously untreated and treated patients with hypertension, 8 weeks of treatment with telmisartan and the $\mathrm{T} / \mathrm{H}$ combination resulted in significant reductions in mean morning ambulatory BP, daytime ambulatory BP, 24-hour ambulatory BP, and clinic BP. ${ }^{39}$

\section{Comparison with other SPCs}

There are currently no studies directly comparing the T/A SPC with SPCs of other antihypertensive drugs. However, in patients who failed to achieve BP goals after at least 2 months' treatment with $5 \mathrm{mg}$ amlodipine plus $80 \mathrm{mg}$ valsartan or $8 \mathrm{mg}$ candesartan, replacement of valsartan or candesartan with telmisartan $40 \mathrm{mg}$ was reported to reduce significantly both mean clinic SBP and DBP at 4, 8, and 12 weeks of treatment. ${ }^{40}$ Similarly, replacement of valsartan $80 \mathrm{mg}$ or candesartan $8 \mathrm{mg}$ after at least 2 months of treatment with telmisartan $40 \mathrm{mg}$ in amlodipine $5 \mathrm{mg}$-treated elderly patients with hypertension resulted in significant reduction in morning home SBP and evening home SBP and DBP at 12 weeks, and a significant increase in serum adiponectin level, suggesting beneficial cardiometabolic effects with T/A in elderly patients with hypertension. ${ }^{41}$

In two large placebo-controlled trials of 8 weeks' duration in patients with stage 1 or 2 hypertension, $\mathrm{T} / \mathrm{H}$ treatment resulted in significantly higher BP reduction than valsartan/ HCTZ. ${ }^{42,43}$ A pooled analysis of the two studies showed that the significant difference in BP reduction in favor of T80/ H25 was maintained, regardless of age, sex, or race of the patients. ${ }^{44}$ In patients with essential hypertension, the $\mathrm{T} / \mathrm{H}$ SPC was significantly more efficacious than the losartan/ HCTZ SPC in reducing BP during the last 6 hours of the dosing interval, as well as in reducing 24-hour ambulatory BP after 6 weeks of treatment. ${ }^{45-47}$ Similarly, 6 weeks' treatment with the T/H SPC resulted in significantly greater reductions in mean ambulatory BP over the entire 24-hour dosing interval and during the last 6 hours compared with valsartan/ HCTZ, in the SMOOTH (Study of Micardis [telmisartan] in Overweight/Obese Patients with Type 2 Diabetes and Hypertension) trial. ${ }^{48}$ A recent meta-analysis of head-to-head randomized controlled trials of $\mathrm{T} / \mathrm{H}$ versus other $\mathrm{ARBs}$ plus HCTZ therapy for reduction of BP in hypertension showed that telmisartan/HCTZ therapy may reduce SBP and DBP by an additional 2.9 and $1.9 \mathrm{mmHg}$, respectively, over other ARB/HCTZ therapy. ${ }^{49}$

\section{Which combination for which patient?}

The selection of a specific combination is dependent on individual patient factors, including additional $\mathrm{CV}$ risk factors and comorbidities. ${ }^{9}$ Subgroup analyses of the telmisartan trials have shown consistent efficacy for both combinations across a range of patient types.

In hypertensive diabetes patients with microalbuminuria, treatment with $\mathrm{T} / \mathrm{A}$ reduced urinary albumin-excretion rate, in addition to lowering BP. ${ }^{50}$ In a multicenter, open-label clinical trial in the People's Republic of China, involving 13,542 high-risk patients with at least one CV risk factor, long-term T/A treatment was found to be efficacious and well tolerated. ${ }^{51}$ In patients with stage 1 or 2 hypertension and diabetes uncontrolled on amlodipine monotherapy, 8 weeks of treatment with the T/A SPC resulted in a significantly higher reduction in SBP and in more patients achieving their BP goal. The results were similar in the subpopulation of obese patients. ${ }^{52}$ In a post hoc analysis of data from patients stratified into subpopulations based on age, race, coexisting diabetes, obesity, metabolic syndrome, renal impairment, and elevated baseline SBP, it was seen that BP reductions, goalattainment rate, and response rate obtained with T80/A10 in these added-risk patients were similar to those observed in the overall population. ${ }^{53}$ Another post hoc analysis of data pooled from clinical studies of the T/A SPC on hypertensive patients with metabolic risk factors (obesity, diabetes, or both), showed that in patients uncontrolled on monotherapy, $\mathrm{BP}$ reductions and goal-rate achievement with T/A were similarly high among patients with and without the presence of metabolic risk factors; particularly large reductions were recorded among patients with severe hypertension (defined as $\mathrm{SBP} \geq 180 \mathrm{mmHg}) .{ }^{54}$ The same post hoc analysis also showed that in hypertensive patients with metabolic risk factors, BP reductions with the T/A SPC were maintained throughout the 24-hour dosing period, and 24-hour goal rates were obtained in a high proportion of patients. ${ }^{54}$

In patients with moderate-to-severe hypertension, a prespecified analysis showed that the T80/H25 SPC treatment resulted in significantly higher BP reductions than T80 monotherapy, regardless of the patients' sex, age, race, hypertension severity, and previous treatment history (treatment-naive or treated with one or $\geq 2$ antihypertensive agents). ${ }^{55}$ Furthermore, a retrospective analysis showed that in black patients with hypertension and hypertensive patients with concomitant type 
2 diabetes mellitus or moderate or severe renal impairment, T80/H25 resulted in greater reductions in SBP and DBP than telmisartan monotherapy, irrespective of baseline $\mathrm{BP}^{27} \mathrm{~A}$ prespecified subgroup analysis of data from patients with stage 2 or 3 hypertension and $\mathrm{CV}$ disease risk factors, such as diabetes mellitus, low estimated glomerular filtration rate, high body mass index, and high coronary heart disease risk, reported that 6 weeks' treatment with T80/H25 consistently provided greater BP reductions and increased BP goal-attainment rates compared with $\mathrm{T} 80$ monotherapy. ${ }^{56} \mathrm{~A}$ pooled analysis of data from seven studies showed that the efficacy and tolerability of the T/H SPC was similar between younger patients and patients older than 65 years (who may have added CV risk factors and are generally difficult to treat to goal).$^{57}$

Thus, the important consideration in choosing the combination of an ARB plus a CCB versus an ARB plus HCTZ is the risk for associated adverse events with CCBs or HCTZ, and their effect on comorbidities in patients with hypertension. The SPC of an ARB with a CCB is preferable for the treatment of hypertensive patients with prediabetes, ${ }^{58,59}$ diabetes, or metabolic syndrome, due to the metabolic neutrality of both component drugs. ${ }^{60}$ The International Society on Hypertension in Blacks recommends an RAS inhibitor-CCB over an RAS inhibitor-thiazide combination in patients with $\mathrm{BP}>15 />10 \mathrm{mmHg}$ above the goal, in the absence of edema and/or volume-overload states. ${ }^{61}$

The combination of an ARB plus HCTZ should be considered for patients in need of volume reduction, as the combination, in addition to maintaining the volume-reducing efficacy of HCTZ, results in additive BP reduction, and a decrease in the adverse metabolic effects of either drug alone. ${ }^{62}$ Similarly, coadministration of an ARB tends to reverse the potassium loss associated with thiazide diuretics, and thiazide-induced reduction in extracellular fluid-volume reduction and peripheral resistance, and the resultant RAS activation may increase the sensitivity of the angiotensin II type 1 receptor, thereby enhancing response to ARBs. ${ }^{63}$ Diuretics are reported to increase the risk for new-onset diabetes, ${ }^{64,65}$ and RAS inhibitors are known to prevent or delay new-onset diabetes. ${ }^{66} \mathrm{An}$ $\mathrm{ARB} / \mathrm{HCTZ}$ combination is particularly useful for patients with high salt consumption, ${ }^{67}$ common in countries such as the People's Republic of China. ${ }^{68}$

In all the T/A SPC treatment trials, the T/A SPC was associated with a lower incidence of edema than amlodipine monotherapy. ${ }^{26-29,69}$ Similarly, the rates of adverse events with $\mathrm{T} / \mathrm{H}$ combination therapy were comparable with or lower than those reported for placebo or telmisartan monotherapy. ${ }^{27,70}$ A retrospective analysis of 50 studies confirmed that as with telmisartan monotherapy, $\mathrm{T} / \mathrm{H}$ is well tolerated in adult patients of all ages and has a favorable safety and tolerability profile. ${ }^{71}$ In a prespecified analysis of data from patients with moderate-to-severe hypertension, it was observed that mean serum potassium levels were unchanged in older, black, and Asian patient subpopulations receiving T80/H25, and other patient subpopulations receiving T80/H25 had small mean reductions in serum potassium, of $-0.1 \mathrm{mmol} / \mathrm{L} .{ }^{55}$

\section{Discussion}

Telmisartan with either amlodipine or HCTZ in an SPC is equally efficacious and well tolerated at all stages of hypertension and in a wide variety of patient subpopulations, and the rationale for selection of one combination over the other is based on the accompanying comorbidities in hypertensive patients. The results from clinical trials and planned and post hoc pooled analysis of data from these trials show the T/A SPC to be efficacious and well tolerated in hypertensive patients with added risk factors including obesity, diabetes, metabolic syndrome, renal impairment, and elevated $\mathrm{SBP},{ }^{52-54}$ and the $\mathrm{T} / \mathrm{H}$ SPC to be efficacious and well tolerated in hypertensive patients with $\mathrm{CV}$ risk factors including obesity, diabetes, high coronary heart disease risk, and renal impairment. ${ }^{27,55-57}$

Also, in a real-life clinical practice setting, most of the patients on combination therapy were found to be on a combination of an RAS inhibitor with a CCB or a diuretic; of the 552 patients on combination therapy, equal proportions were on a combination of RAS inhibitor plus a $\mathrm{CCB}$ or a diuretic. ${ }^{72}$ At the end of the follow-up, the BP-lowering efficacy was similar between the two combinations, but the incidence of new-onset diabetes was higher with the RAS inhibitor plus diuretic combination. ${ }^{72}$

Due to the nature of existing antihypertensives, and in most cases their single site of action, BP responses are largely unpredictable and wide ranging when administered to a heterogeneous population encompassing many hypertensive phenotypes. ${ }^{73}$ In patients not adequately responding to monotherapy, uptitration or substitution of medication is not always as effective as combination therapy, especially where the phenotype is not known. ${ }^{73}$ Combination therapy works better in these patients because of the pharmacological action on two or more different physiological sites, and the blocking of the counterregulatory responses that occur with monotherapy. ${ }^{73}$ For example, RAS inhibitors may also reduce the unfavorable metabolic side effects of thiazide monotherapy ${ }^{74}$ and CCB-induced peripheral edema. ${ }^{75,76}$ The postcapillary dilation and normalization of hydrostatic pressure induced by RAS inhibitors ${ }^{77}$ compensates for the 
increased capillary pressure and flow with $\mathrm{CCBs}$, which leads to increased permeability and fluid hyperfiltration. ${ }^{78}$ An SPC of an RAS inhibitor plus a CCB is the preferred combination over an RAS inhibitor plus HCTZ in CV high-risk patients and those with evidence of renal disease. ${ }^{19-21}$ The adverse electrolytic changes, including hypokalemia associated with diuretic use, may also be offset with concomitant use of RAS inhibitors.

The benefit of early achievement of BP goal in preventing $\mathrm{CV}$ events was seen in the Valsartan Antihypertensive Long term Use Evaluation (VALUE) study, which showed significant benefits for major $\mathrm{CV}$ outcomes when BP goals were achieved within 6 months of treatment initiation. ${ }^{79}$ Early use of an SPC, including as first-line treatment, is suggested to help to reduce the gap between antihypertensive use and achievement of BP target control. ${ }^{80}$ Indeed, a retrospective analysis of 106,621 patients showed improved CV outcomes with SPCs compared with monotherapy during the first year of treatment. ${ }^{81}$

In addition to early treatment initiation with combination therapy and selection of the most suitable combination based on patient needs, treatment adherence and compliance are also crucial for BP control, to reduce long-term CV morbidity and mortality and to improve quality of life ${ }^{82}$ Compared with free-drug combinations, SPCs of antihypertensive agents are associated with a significant improvement in compliance, ${ }^{83}$ adherence rates, ${ }^{59,84,85}$ lower health-care costs, ${ }^{86}$ and significantly higher goal rates. ${ }^{87}$ The reduced pill burden, simplified treatment regimens, and improved treatment adherence with SPCs is expected to result in better BP control and long-term $\mathrm{CV}$ risk reduction. ${ }^{88}$

\section{Conclusion}

SPCs of telmisartan with amlodipine or HCTZ provide better efficacy than the respective monotherapies in patients at all stages of hypertension, as well as in those with added risk factors, including obesity, diabetes, or metabolic syndrome. The SPCs are associated with a lower incidence of adverse effects, such as edema and hypokalemia, compared with amlodipine and HCTZ monotherapy.

\section{Acknowledgments}

The authors were fully responsible for all content and editorial decisions, were involved at all stages of manuscript development, and have approved the final version. Medical writing assistance, supported financially by Boehringer Ingelheim Pharma GmbH \& Co. KG., was provided by Lakshmi Venkatraman, $\mathrm{PhD}$, and Tom Rees, $\mathrm{PhD}$, of Parexel during the preparation of this article. The authors meet criteria for authorship recommended by the International Committee of Medical Journal Editors (ICMJE), and received no compensation related to the development of the manuscript. Boehringer Ingelheim Pharma GmbH \& Co. KG., was given the opportunity to check the data used in the manuscript for factual accuracy only.

\section{Disclosure}

Dr Segura has no conflict of interest. Professor Ruilope has received consulting and lecture fees from Boehringer Ingelheim.

\section{References}

1. Hajjar I, Kotchen TA. Trends in prevalence, awareness, treatment, and control of hypertension in the United States, 1988-2000. JAMA. 2003;290(2):199-206

2. Guo F, He D, Zhang W, Walton RG. Trends in prevalence, awareness, management, and control of hypertension among United States adults, 1999 to 2010. J Am Coll Cardiol. 2012;60(7):599-606.

3. Okonofua EC, Simpson KN, Jesri A, Rehman SU, Durkalski VL, Egan BM. Therapeutic inertia is an impediment to achieving the Healthy People 2010 blood pressure control goals. Hypertension. 2006;47(3): 345-351.

4. Wang S, Berbari N, Choi D, et al. Managing hypertension in patients with or without comorbidities in a teaching hospital outpatient setting. $P \& T$ 2007;32(1):32-42.

5. Gradman AH, Basile JN, Carter BL, Bakris GL. Combination therapy in hypertension. J Am Soc Hypertens. 2010;4(1):42-50.

6. Corrao G, Nicotra F, Parodi A, et al. Cardiovascular protection by initial and subsequent combination of antihypertensive drugs in daily life practice. Hypertension. 2011;58(4):566-572.

7. Gradman AH, Parisé H, Lefebvre P, Falvey H, Lafeuille MH, Duh MS Initial combination therapy reduces the risk of cardiovascular events in hypertensive patients: a matched cohort study. Hypertension 2013;61(2):309-318.

8. Mancia G, De Backer G, Dominiczak A, et al. 2007 Guidelines for the management of arterial hypertension: the Task Force for the Management of Arterial Hypertension of the European Society of Hypertension (ESH) and of the European Society of Cardiology (ESC). Eur Heart J. 2007;28(12):1462-1536.

9. Mancia G, Laurent S, Agabiti-Rosei E, et al. Reappraisal of European guidelines on hypertension management: a European Society of Hypertension Task Force document. J Hypertens. 2009;27(11):2121-2158.

10. ONTARGET Investigators, Yusuf S, Teo KK, et al. Telmisartan, ramipril, or both in patients at high risk for vascular events. $N$ Engl $J$ Med. 2008;358(15):1547-1559.

11. [No authors listed]. Effects of ramipril on cardiovascular and microvascular outcomes in people with diabetes mellitus: results of the HOPE study and MICRO-HOPE substudy. Heart Outcomes Prevention Evaluation Study Investigators. Lancet. 2000;355(9200):253-259.

12. Di Somma S, Sentimentale A. New onset of type 2 diabetes mellitus during antihypertensive therapy. High Blood Press Cardiovasc Prev. 2006; 13(1):29-36.

13. Corrao G, Zambon A, Parodi A, et al. Discontinuation of and changes in drug therapy for hypertension among newly-treated patients: a population-based study in Italy. J Hypertens. 2008;26(4):819-824.

14. Lacourcière Y. A multicenter, randomized, double-blind study of the antihypertensive efficacy and tolerability of irbesartan in patients aged $\geq 65$ years with mild to moderate hypertension. Clin Ther. 2000;22(10):1213-1224.

15. Burnier M, Maillard M. The comparative pharmacology of angiotensin II receptor antagonists. Blood Press Suppl. 2001;1:6-11. 
16. Boehringer Ingelheim. Micardis [summary of product characteristics]. Ingelheim, Germany: Boehringer Ingelheim International; 2008.

17. Boehringer Ingelheim. Micardis [prescribing information]. Ingelheim, Germany: Boehringer Ingelheim International; 2012.

18. Gradman AH, Basile JN, Carter BL, Bakris GL. Combination therapy in hypertension. J Clin Hypertens (Greenwich). 2011;13(3):146-154.

19. Jamerson K, Weber MA, Bakris GL, et al. Benazepril plus amlodipine or hydrochlorothiazide for hypertension in high-risk patients. $N$ Engl J Med. 2008;359(23):2417-2428.

20. Bakris GL, Sarafidis PA, Weir MR, et al. Renal outcomes with different fixed-dose combination therapies in patients with hypertension at high risk for cardiovascular events (ACCOMPLISH): a prespecified secondary analysis of a randomised controlled trial. Lancet. 2010;375(9721): $1173-1181$.

21. Mallat SG. What is a preferred angiotensin II receptor blocker-based combination therapy for blood pressure control in hypertensive patients with diabetic and non-diabetic renal impairment? Cardiovasc Diabetol. 2012;11:32.

22. Chalmers J, Joshi R, Kengne AP, MacMahon S. Blood pressure lowering with fixed combination perindopril-indapamide: key findings from ADVANCE. J Hypertens Suppl. 2008;26(2):S11-S15.

23. PROGRESS Collaborative Group. Randomised trial of a perindoprilbased blood-pressure-lowering regimen among 6,105 individuals with previous stroke or transient ischaemic attack. Lancet. 2001;358(9287): 1033-1041.

24. Beckett NS, Peters R, Fletcher AE, et al. Treatment of hypertension in patients 80 years of age or older. $N$ Engl J Med. 2008;358(18): 1887-1898.

25. Bulpitt CJ, Beckett NS, Peters R, et al. Blood pressure control in the Hypertension in the Very Elderly Trial (HYVET). J Hum Hypertens. 2012;26(3):157-163.

26. Neldam S, Lang M, Jones R. Telmisartan and amlodipine single-pill combinations vs amlodipine monotherapy for superior blood pressure lowering and improved tolerability in patients with uncontrolled hypertension: results of the TEAMSTA-5 study. J Clin Hypertens (Greenwich). 2011;13(7):459-466.

27. Neldam S, Schumacher H, Guthrie R. Telmisartan $80 \mathrm{mg}$ /hydrochlorothiazide $25 \mathrm{mg}$ provides clinically relevant blood pressure reductions across baseline blood pressures. Adv Ther. 2012;29(4):327-338.

28. Neutel JM, Mancia G, Black HR, et al. Single-pill combination of telmisartan/amlodipine in patients with severe hypertension: results from the TEAMSTA severe HTN study. J Clin Hypertens (Greenwich). 2012;14(4):206-215.

29. Littlejohn TW III, Majul CR, Olvera R, et al. Telmisartan plus amlodipine in patients with moderate or severe hypertension: results from a subgroup analysis of a randomized, placebo-controlled, parallel-group, $4 \times 4$ factorial study. Postgrad Med. 2009;121(2):5-14.

30. Neldam S, Dahlof B, Oigman W, Schumacher H. Early combination therapy with telmisartan plus amlodipine for rapid achievement of blood pressure goals. Int J Clin Pract. In press 2013.

31. Lacourcière Y, Tytus R, O'Keefe D, Lenis J, Orchard R, Martin K. Efficacy and tolerability of a fixed-dose combination of telmisartan plus hydrochlorothiazide in patients uncontrolled with telmisartan monotherapy. J Hum Hypertens. 2001;15(11):763-770.

32. Lacourcière Y. A new fixed-dose combination for added blood pressure control: telmisartan plus hydrochlorothiazide. J Int Med Res. 2002;30(4):366-379.

33. Lacourcière Y, Martin K. Comparison of a fixed-dose combination of $40 \mathrm{mg}$ telmisartan plus $12.5 \mathrm{mg}$ hydrochlorothiazide with $40 \mathrm{mg}$ telmisartan in the control of mild to moderate hypertension. Am J Ther. 2002;9(2):111-117.

34. McGill JB, Reilly PA. Telmisartan plus hydrochlorothiazide versus telmisartan or hydrochlorothiazide monotherapy in patients with mild to moderate hypertension: a multicenter, randomized, doubleblind, placebo-controlled, parallel-group trial. Clin Ther. 2001;23(6): 833-850.
35. Neldam S, Edwards C. Results of increasing doses of hydrochlorothiazide in combination with an angiotensin receptor blocker in patients with uncontrolled hypertension. J Clin Hypertens (Greenwich). 2008;10(8): 612-618.

36. Chobanian AV, Bakris GL, Black HR, et al. Seventh report of the Joint National Committee on Prevention, Detection, Evaluation, and Treatment of High Blood Pressure. Hypertension. 2003;42(6): $1206-1252$.

37. Zhu DL, Bays H, Gao P, Mattheus M, Voelker B, Ruilope L. Efficacy and tolerability of initial therapy with single-pill combination telmisartan/hydrochlorothiazide $80 / 25 \mathrm{mg}$ in patients with grade 2 or 3 hypertension: a multinational, randomized, double-blind, activecontrolled trial. Clin Ther. 2012;34(7):1613-1624.

38. White WB, Littlejohn TW, Majul CR, et al. Effects of telmisartan and amlodipine in combination on ambulatory blood pressure in stages 1-2 hypertension. Blood Press Monit. 2010;15(4):205-212.

39. Parati G, Bilo G, Redon J. The effects of telmisartan alone or with hydrochlorothiazide on morning and 24-h ambulatory BP control: results from a practice-based study (SURGE 2). Hypertens Res. 2012;36(4):322-327.

40. Bekki H, Yamamoto K, Sone M, et al. Efficacy of combination therapy with telmisartan plus amlodipine in patients with poorly controlled hypertension. Oxid Med Cell Longev. 2010;3(5):342-346.

41. Bekki H, Yamamoto K, Sone M, et al. Beneficial cardiometabolic actions of telmisartan plus amlodipine therapy in elderly patients with poorly controlled hypertension. Clin Cardiol. 2011;34(4):261-265.

42. White WB, Punzi HA, Murwin D, Koval SE, Davidai G, Neutel JM. Effects of the angiotensin II receptor blockers telmisartan vs valsartan in combination with hydrochlorothiazide $25 \mathrm{mg}$ once daily for the treatment of hypertension. J Clin Hypertens (Greenwich). 2006;8(9): 626-633.

43. White WB, Murwin D, Chrysant SG, Koval SE, Davidai G, Guthrie R. Effects of the angiotensin II receptor blockers telmisartan versus valsartan in combination with hydrochlorothiazide: a large, confirmatory trial. Blood Press Monit. 2008;13(1):21-27.

44. White WB, Davidai G, Schumacher H. Impact of angiotensin receptor blockade in combination with hydrochlorothiazide $25 \mathrm{mg}$ in 2121 patients with stage 1-2 hypertension. J Hum Hypertens. 2009; 23(12):817-825.

45. Lacourcière Y, Gil-Extremera B, Mueller O, Byrne M, Williams L. Efficacy and tolerability of fixed-dose combinations of telmisartan plus HCTZ compared with losartan plus HCTZ in patients with essential hypertension. Int J Clin Pract. 2003;57(4):273-279.

46. Lacourcière Y, Neutel JM, Schumacher H. Comparison of fixed-dose combinations of telmisartan/hydrochlorothiazide 40/12.5 mg and $80 / 12.5 \mathrm{mg}$ and a fixed-dose combination of losartan/hydrochlorothiazide $50 / 12.5 \mathrm{mg}$ in mild to moderate essential hypertension: pooled analysis of two multicenter, prospective, randomized, openlabel, blinded-end point (PROBE) trials. Clin Ther. 2005;27(11): 1795-1805.

47. Neutel JM, Littlejohn TW, Chrysant SG, Singh A. Telmisartan/ hydrochlorothiazide in comparison with losartan/hydrochlorothiazide in managing patients with mild-to-moderate hypertension. Hypertens Res. 2005;28(7):555-563.

48. Sharma AM, Davidson J, Koval S, Lacourcière Y. Telmisartan/ hydrochlorothiazide versus valsartan/hydrochlorothiazide in obese hypertensive patients with type 2 diabetes: the SMOOTH study. Cardiovasc Diabetol. 2007;6:28.

49. Takagi H, Mizuno Y, Goto SN, Umemoto T. A meta-analysis of randomized head-to-head trials of telmisartan versus other angiotensin II receptor blocker in combination with hydrochlorothiazide for reduction of blood pressure. Int J Cardiol. Epub November 28, 2012.

50. Fogari R, Derosa G, Zoppi A, et al. Effect of telmisartan-amlodipine combination at different doses on urinary albumin excretion in hypertensive diabetic patients with microalbuminuria. Am J Hypertens. 2007;20(4):417-422. 
51. Ma L, Wang W, Zhao Y, et al. Combination of amlodipine plus angiotensin receptor blocker or diuretics in high-risk hypertensive patients: a 96-week efficacy and safety study. Am J Cardiovasc Drugs. 2012;12(2):137-142.

52. Sharma AM, Bakris G, Neutel JM, et al. Single-pill combination of telmisartan/amlodipine versus amlodipine monotherapy in diabetic hypertensive patients: an 8-week randomized, parallel-group, doubleblind trial. Clin Ther. 2012;34(3):537-551.

53. Guthrie RM, Dahlof B, Jamerson KA, et al. Efficacy and tolerability of telmisartan plus amlodipine in added-risk hypertensive patients. $\mathrm{Curr}$ Med Res Opin. 2011;27(10):1995-2008.

54. Ley L, Schumacher H. Telmisartan plus amlodipine single-pill combination for the management of hypertensive patients with a metabolic risk profile (added-risk patients). Curr Med Res Opin. 2013;29(1): 41-53.

55. Zhu DL, Bays H, Gao P, Mattheus M, Voelker B, Ruilope L. Efficacy and tolerability of a single-pill combination of telmisartan $80 \mathrm{mg}$ and hydrochlorothiazide $25 \mathrm{mg}$ according to age, sex, race, hypertension severity, and previous antihypertensive use: planned analyses of a randomized trial. Integr Blood Press Control. 2013;6:1-14.

56. Bays H, Gao P, Voelker B, Mattheus M, Ruilope L, Zhu D. Efficacy of single-pill combination of telmisartan $80 \mathrm{mg}$ and hydrochlorothiazide $25 \mathrm{mg}$ in patients with cardiovascular disease risk factors: a prospective subgroup analysis of a randomized, double-blind, controlled trial. Int J Hypertens. 2013;2013:749830. doi: 10.1155/2013/749830.

57. Kjeldsen SE, Schumacher H, Neldam S, Guthrie RM. Telmisartan/ hydrochlorothiazide combination therapy for the treatment of hypertension: a pooled analysis in older and younger patients. J Clin Hypertens (Greenwich). 2013;15(6):380-388.

58. Garber AJ, Handelsman Y, Einhorn D, et al. Diagnosis and management of prediabetes in the continuum of hyperglycemia: when do the risks of diabetes begin? A consensus statement from the American College of Endocrinology and the American Association of Clinical Endocrinologists. Endocr Pract. 2008;14(7):933-946.

59. Mancia G, Fagard R, Narkiewicz K, et al. 2013 ESH/ESC Guidelines for the management of arterial hypertension: The task force for the management of arterial hypertension of the European Society of Hypertension (ESH) and of the European Society of Cardiology (ESC). Eur Heart J. Epub June 14, 2013.

60. Chrysant SG. Amlodipine/ARB fixed-dose combinations for the treatment of hypertension: focus on amlodipine/olmesartan combination. Drugs Today (Barc). 2008;44(6):443-453.

61. Flack JM, Sica DA, Bakris G, et al. Management of high blood pressure in blacks: an update of the International Society on Hypertension in Blacks consensus statement. Hypertension. 2010;56(5):780-800.

62. Neutel JM, Smith DH, Reilly PA. The efficacy and safety of telmisartan compared to enalapril in patients with severe hypertension. Int J Clin Pract. 1999;53(3):175-178.

63. Meredith PA. Angiotensin II receptor antagonists alone and combined with hydrochlorothiazide: potential benefits beyond the antihypertensive effect. Am J Cardiovasc Drugs. 2005;5(3):171-183.

64. Taylor EN, Hu FB, Curhan GC. Antihypertensive medications and the risk of incident type 2 diabetes. Diabetes Care. 2006;29(5):1065-1070.

65. Salvetti A, Ghiadoni L. Thiazide diuretics in the treatment of hypertension: an update. J Am Soc Nephrol. 2006;17(4 Suppl 2): S25-S29.

66. Basile JN. Antihypertensive therapy, new-onset diabetes, and cardiovascular disease. Int J Clin Pract. 2009;63(4):656-666.

67. Yoshimura M, Kawai M. Synergistic inhibitory effect of angiotensin II receptor blocker and thiazide diuretic on the tissue renin-angiotensinaldosterone system. J Renin Angiotensin Aldosterone Syst. 2010;11(2): 124-126.

68. Liu Z. Dietary sodium and the incidence of hypertension in the Chinese population: a review of nationwide surveys. Am J Hypertens. 2009;22(9):929-933.
69. Littlejohn TW III, Majul CR, Olvera R, et al. Results of treatment with telmisartan-amlodipine in hypertensive patients. J Clin Hypertens (Greenwich). 2009;11(4):207-213.

70. Plosker GL, White WB. Telmisartan/hydrochlorothiazide: a review of its use as fixed-dose combinations in essential hypertension. Drugs. 2008;68(13):1877-1899

71. Schumacher H, Mancia G. The safety profile of telmisartan as monotherapy or combined with hydrochlorothiazide: a retrospective analysis of 50 studies. Blood Press Suppl. 2008;1:32-40.

72. Cerezo C, Sevillano A, Guerrero L, et al. Does hypertensive patient fenotype influence when selecting the best combination of antihypertensive drugs? Journal of Hypertension Volume 31, e-Supplement A, June 2013.

73. Sever PS, Messerli FH. Hypertension management 2011: optimal combination therapy. Eur Heart J. 2011;32(20):2499-2506.

74. Kjeldsen SE, Os I, Høieggen A, Beckey K, Gleim GW, Oparil S. Fixeddose combinations in the management of hypertension: defining the place of angiotensin receptor antagonists and hydrochlorothiazide. Am J Cardiovasc Drugs. 2005;5(1):17-22.

75. Makani H, Bangalore S, Romero J, Wever-Pinzon O, Messerli FH. Effect of renin-angiotensin system blockade on calcium channel blockerassociated peripheral edema. Am J Med. 2011;124(2):128-135.

76. Oparil S, Weber M. Angiotensin receptor blocker and dihydropyridine calcium channel blocker combinations: an emerging strategy in hypertension therapy. Postgrad Med. 2009;121(2):25-39.

77. de la Sierra A. Mitigation of calcium channel blocker-related oedema in hypertension by antagonists of the renin-angiotensin system. J Hum Hypertens. 2009;23(8):503-511.

78. Pedrinelli R, Dell'Omo G, Mariani M. Calcium channel blockers, postural vasoconstriction and dependent oedema in essential hypertension. J Hum Hypertens. 2001;15(7):455-461.

79. Weber MA, Julius S, Kjeldsen SE, et al. Blood pressure dependent and independent effects of antihypertensive treatment on clinical events in the VALUE trial. Lancet. 2004;363(9426):2049-2051.

80. Kjeldsen SE, Messerli FH, Chiang CE, Meredith PA, Liu L. Are fixeddose combination antihypertensives suitable as first-line therapy? Curr Med Res Opin. 2012;28(10):1685-1697.

81. Egan BM, Bandyopadhyay D, Shaftman SR, Wagner CS, Zhao Y, Yu-Isenberg KS. Initial monotherapy and combination therapy and hypertension control the first year. Hypertension. 2012;59(6): 1124-1131.

82. Mazzaglia G, Ambrosioni E, Alacqua M, et al. Adherence to antihypertensive medications and cardiovascular morbidity among newly diagnosed hypertensive patients. Circulation. 2009;120(16):1598-1605.

83. Gupta AK, Arshad S, Poulter NR. Compliance, safety, and effectiveness of fixed-dose combinations of antihypertensive agents: a meta-analysis. Hypertension. 2010;55(2):399-407.

84. Gerbino PP, Shoheiber O. Adherence patterns among patients treated with fixed-dose combination versus separate antihypertensive agents. Am J Health Syst Pharm. 2007;64(12):1279-1283.

85. Zeng F, Patel BV, Andrews L, Frech-Tamas F, Rudolph AE. Adherence and persistence of single-pill $\mathrm{ARB} / \mathrm{CCB}$ combination therapy compared to multiple-pill ARB/CCB regimens. Curr Med Res Opin. 2010;26(12): 2877-2887.

86. Dickson M, Plauschinat CA. Compliance with antihypertensive therapy in the elderly: a comparison of fixed-dose combination amlodipine/ benazepril versus component-based free-combination therapy. $A m \mathrm{~J}$ Cardiovasc Drugs. 2008;8(1):45-50.

87. Chang J, Yang W, Fellers T, et al. Chart review of patients on valsartan-based single-pill combinations vs ARB-based free combinations for BP goal achievement. Curr Med Res Opin. 2010;26(9): 2203-2212.

88. Bangalore S, Ley L. Improving treatment adherence to antihypertensive therapy: the role of single-pill combinations. Expert Opin Pharmacother. 2012;13(3):345-355. 


\section{Publish your work in this journal}

Vascular Health and Risk Management is an international, peerreviewed journal of therapeutics and risk management, focusing on concise rapid reporting of clinical studies on the processes involved in the maintenance of vascular health; the monitoring, prevention and treatment of vascular disease and its sequelae; and the involvement of

metabolic disorders, particularly diabetes. This journal is indexed on PubMed Central and MedLine. The manuscript management system is completely online and includes a very quick and fair peer-review system, which is all easy to use. Visit http://www.dovepress.com/ testimonials.php to read real quotes from published authors.

Submit your manuscript here: http://www.dovepress.com/vascular-health-and-risk-management-journal 